\title{
Variation of Dominant Instability Mode with Fuel Configuration in an Inverted Coaxial Injector
}

\author{
Abhinav Dasari* and Mirko Gamba ${ }^{\dagger}$ \\ The University of Michigan, Department of Aerospace Engineering, 1320 Beal Avenue, Ann Arbor, MI 48109
}

\begin{abstract}
We explore the steady and unsteady flame properties of a coaxial jet flame in a moderate pressure combustor with a single shear coaxial injector. Significant flame structure modifications are observed in $\mathrm{H}_{2} / \mathrm{O}_{2}$ and $\mathrm{CH}_{4} / \mathrm{O}_{2}$ flames at fuel lean conditions over a range of pressure conditions varying from near-atmospheric to about 8 atm. The different stages of flame evolution in $\mathrm{H}_{2} / \mathrm{O}_{2}$ flames correspond very well with the different phases of pressure cycles. $\mathrm{CH}_{4} / \mathrm{O}_{2}$ flames have a different structure and evolution process as compared to that of $\mathrm{H}_{2} / \mathrm{O}_{2}$ flames and also exhibit higher instability limits. The critical equivalence ratio, separating steady and unsteady operation, increases with increase in pressure.
\end{abstract}

\section{Introduction}

Combustion instabilities, in the context of rocket propulsion, were first observed in the 1930s. ${ }^{1}$ According to Lord Rayleigh, the constructive coupling between an unsteady heat release rate and acoustic waves is the cause of such instabilities. ${ }^{2}$ During unstable combustion, the frequency spectra of chamber pressure shows distinct frequencies that contain large amounts of energy. These frequencies are typically categorized into three different types. Low frequency instabilities (chugging, groaning or motor-boating), in the range of a few hundred hertz, can occur due to the coupling of the combustion process with the injector structure or chamber pressure, leading to nonuniform propellant injection and flow rate oscillations. High frequency instabilities (screaming, organing or screeching), in the range of thousands of hertz, are often cause by the excitation of the acoustic eigenmode of the combustion chamber by the combustion process. For this reason, they are also referred to as thermoacoustic, or simply, acoustic instabilities. Intermediate instabilities (buzzing), in the range of several hundred to a few thousand Hertz can have many different causes, entropy wave caused by cyclic mixture ratio variations being one of them. ${ }^{3}$

Despite recent advancements in stability modeling, combustion instabilities are typically the most important risk in LRE development programs. Almost all methods of stabilization are based on trial-and-error or empirical observations. Understanding the triggering and sustaining mechanisms can help in better prediction and control of such instabilities.

The design of modern engines, with high density of energy release in a volume with relatively low losses, favors the excitation and sustenance of such oscillations. ${ }^{1}$ In gas turbines, development of high bypass engines created conditions favorable for low frequency longitudinal vibrations to exist, which could not be eliminated by simple geometry changes. With the recent thrust towards lean, low-temperature premixed combustion for emission reduction, the potential for instabilities in gas turbines increases. The F-1 engine, developed to satisfy the heavy lift requirement of the Apollo Program, suffered serious erosion and damage of the injector face during its development process due to the presence of strong instabilities.

Different instability modes are naturally observed in our experiments with an single-shear coaxial injector at the Michigan Single Element Injector Facility (MSEIF). Due to their relative simplicity, shear coaxial injectors are common in a wide variety of applications, thus making the study of potential instabilities in such systems of practical importance and relevance. Past experiments had shown the presence of thermoacoustic instabilities under certain operating conditions when hydrogen was used as the fuel. ${ }^{5,6}$ There has been a

\footnotetext{
${ }^{*}$ Graduate Student, Department of Aerospace Engineering, 1320 Beal Ave., University of Michigan, Ann Arbor, MI 48109, Student Member AIAA.

${ }^{\dagger}$ Assistant Professor, Department of Aerospace Engineering, 1320 Beal Ave., University of Michigan, Ann Arbor, MI 48109, Member AIAA.
} 
push for hydrocarbon fuels in commercial systems. With that motivation, we have recently begun looking at the instability characteristics of our combustor with hydrocarbons instead of hydrogen as fuel. The use of methane shows the presence of a qualitatively different instability mode without any geometrical modifications to the experimental setup.

Observations of the distribution of $\mathrm{OH}$ and $\mathrm{CH}_{2} \mathrm{O}$ in recent experiments to explore the effect of confinement on flame structure and instability also raises interesting questions about flame anchoring and re-ignition. By trying to understand how instability modes in the combustor depend on the propellants and confinement, we aim to take a step towards improving our understanding regarding how different instabilities are triggered and sustained.

\section{Experimental setup}

\section{A. Experimental facility}

The Michigan Single Element Injector experiment is a laboratory-scale gas phase single element rocket engine model capable of operations at chamber pressures up to $10 \mathrm{~atm}$. The facility was originally designed by Schumaker ${ }^{7,8}$ based on work conducted at Penn State and NASA Marshall. ${ }^{9-11}$ It was originally developed to study mixing in reacting and non-reacting coaxial jets under steady operation, and has been described in detail by Schumaker. ${ }^{8}$ A schematic diagram of the facility is shown in Figure 1.

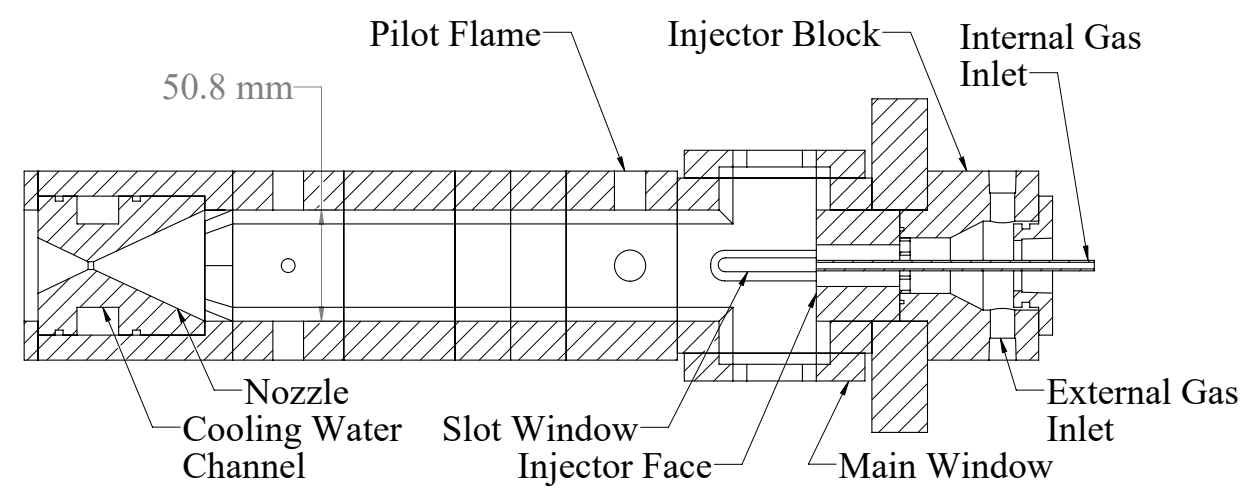

Figure 1. Schematic diagram of the Michigan Single Element Injector Facility.

The rocket combustor is of modular design. It has windows for optical access for laser-based diagnostics, an injection block with a single shear coaxial jet injector located at its center, and a water cooled nozzle block. As the entire system is not actively cooled, test time is limited by the heating capacity of the thermal mass of the engine.

The coaxial jet configuration is composed of concentric tubes secured into the injector block. With this setup, different coaxial injector configurations with different inner and outer diameters can be evaluated. For the reacting flow studies, the inner tube delivers the oxidizer $\left(\mathrm{O}_{2}\right)$ and the surrounding annulus delivers the fuel $\left(\mathrm{H}_{2}, \mathrm{CH}_{4}\right.$, etc.). For all cases in the present study, the inner tube has an inner diameter $D_{i}$ of $3.66 \mathrm{~mm}$ and an outer diameter of $4.76 \mathrm{~mm}$, and the annulus has a diameter $D_{o}$ of $6.73 \mathrm{~mm}$. The injector assembly sits flush with the floor of the combustion chamber and a pilot flame system is used for igniting the coaxial jet.

\section{B. Qualitative OH PLIF}

Planar laser-induced fluorescence (PLIF) imaging of $\mathrm{OH}$ is used to generate a qualitative distribution of the hydroxyl radical within the combustor during reacting operation. A typical PLIF system composed of a doubled tunable dye laser pumped by the second harmonic of a Nd:YAG pulsed laser is used to excite the $\mathrm{A}-\mathrm{X}(1,0) \mathrm{Q}_{1}(7)$ or $\mathrm{Q}_{1}(6)$ transition line of $\mathrm{OH}$ near $283 \mathrm{~nm}$, which generates the LIF signal. In our initial experiments we used the $\mathrm{Q}_{1}(7)$ transition, but for some of the later experiments, especially the $\mathrm{CH}_{4} / \mathrm{O}_{2}$ ones, the $\mathrm{Q}_{1}(6)$ transition line was employed because the signals obtained were much higher. Imaging of the fluorescence is carried out with an intensified CCD camera. The camera is gated to $90 \mathrm{~ns}$ and a $310 \mathrm{~nm}$ (10 
nm FWHM) bandpass filter is used to block unwanted light. With run times of $12 \mathrm{~s}$ and a frame rate of $5 \mathrm{~Hz}$, at least 30 useful images are captured during each run, after dropping data from the initial startup transients. As the images are acquired at only $5 \mathrm{~Hz}$, these image sequences are not time resolved.

\section{Qualitative $\mathrm{CH}_{2} \mathrm{O}$ PLIF}

$\mathrm{CH}_{2} \mathrm{O}$ is an important intermediate in hydrocarbon oxidation. In methane combustion, the formation of formaldehyde is dominated by the reaction between methyl radical and oxygen atom and its destruction is dominated by hydrogen abstraction. ${ }^{12,13}$ Formaldehyde is used as an indicator of cool-flame regions and the first stage of combustion processes, and the detection of this molecule is used to understand the initiation and evolution of combustion ${ }^{14}$

The third harmonic of a Nd:YAG laser is used to excite a weak rotational transition in formaldehyde. ${ }^{12,15}$ Fluorescence is imaged onto an intensified CCD camera gated at 90 ns. An interference filter centered at $400 \mathrm{~nm}(50 \mathrm{~nm}$ FWHM) is used to filter out most of the interferences and flame luminosity. Some amount of broadband PAH fluorescence was also possibly transmitted by the filter, but no corrections were made to account for this. These images are acquired at $5 \mathrm{~Hz}$, thus they do not temporally resolve the evolution of the coaxial flame.

\section{High-speed chemiluminescence and pressure measurements}

High-speed pressure and chemiluminescence measurements are made at $10 \mathrm{kHz}$ to obtain a temporally resolved description of the unsteady combustion process during reacting experiments. A Cooper PTG-404A, connected to the chamber by a long tube, is used to record static pressure within the chamber. Kulite ETM-375 transducers placed at different locations along the combustion chamber, as shown in Figure 2, are used to record dynamic pressure data at different longitudinal locations within the combustion chamber, and at the inner stream (oxidizer) inlet tube and the fuel plenum (of the outer stream).

The rocket is preheated to $\sim 65^{\circ} \mathrm{C}$ using a heating tape to reduce water condensation inside the combustion chamber and on the windows during runs. This introduces a thermal shift in the readings of the Kulite transducers. This shift is zeroed out prior to analysis by using the measurements from the Cooper transducer as a reference.

Broadband chemiluminescence during $\mathrm{H}_{2} / \mathrm{O}_{2}$ runs is recorded using a high-speed CMOS camera. During $\mathrm{CH}_{4} / \mathrm{O}_{2}$ runs, $\mathrm{OH}^{*}$ chemiluminescence is recorded using suitable filters and a high-speed CMOS camera coupled to a high-speed image intensifier.

\section{E. Experimental conditions}

To explore the stability limits and pressure dependence of $\mathrm{H}_{2} / \mathrm{O}_{2}$ cases, the range of test cases has been expanded from past experiments. ${ }^{5}$ Tests were run at pressures ranging from just over atmospheric to about 8 atm. Runs were made at different equivalence ratios and mass flow rates. The focus is particularly on near-stoichiometric and fuel-lean cases. For most cases, the inner stream Reynolds number $R e_{i}$ varies from 11,000 to 65,000 and the outer stream Reynolds number $R e_{o}$ varies from 700 to 5,000. Fuel-to-oxidizer velocity differences $\Delta v$ range from $-55 \mathrm{~m} / \mathrm{s}$ to $30 \mathrm{~m} / \mathrm{s}$.

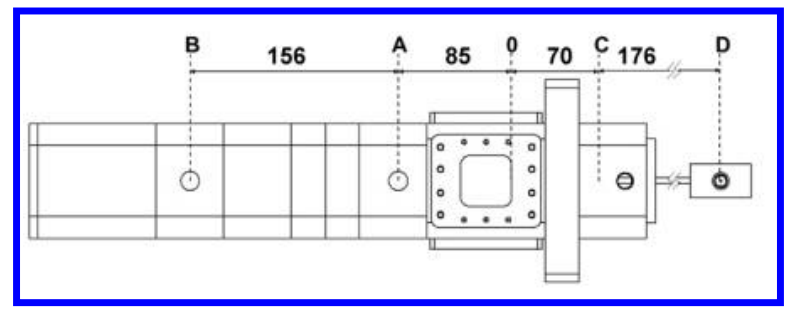

Figure 2. Locations (in $\mathrm{mm}$ ) of pressure transducers in the setup. 0 represents the location of the injector face. Transducers A and B are on the same side of the combustor. Transducer $C$ is located in the fuel (external gas) plenum and is on a side perpendicular to that of transducers $A$ and $B$ because of space restrictions. Transducer $\mathrm{D}$ is attached to a pressure tap on the oxidizer (internal gas) line and faces the same way as transducers $\mathrm{A}$ and $\mathrm{B}$. 


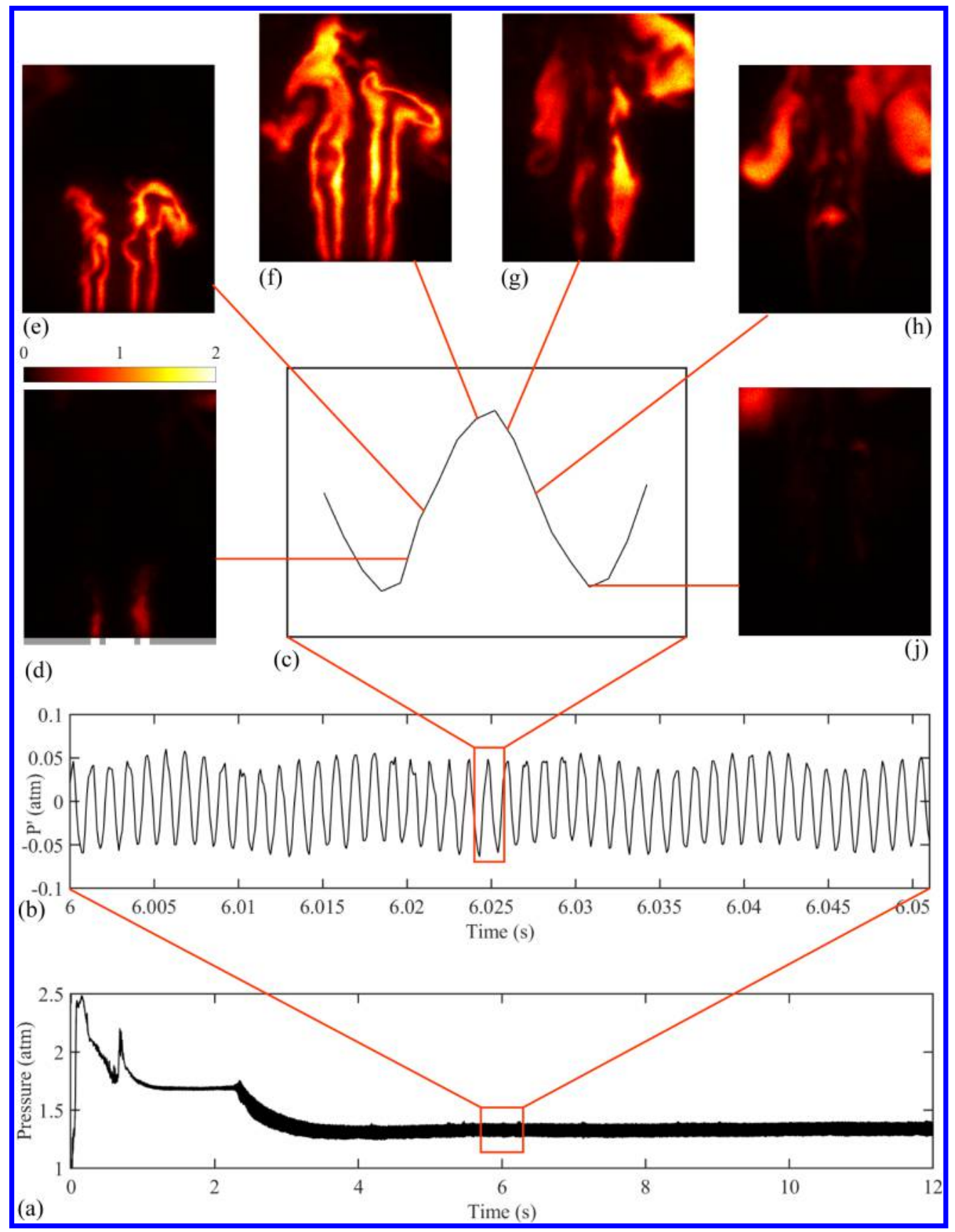

Figure 3. A typical pressure trace within the combustor (a) shows the presence of a high frequency ( $\sim 1$ $\mathrm{kHz})$ oscillation whose amplitude is modulated at a lower frequency $(\sim 100 \mathrm{~Hz})(\mathrm{b})$. Different phases of a pressure fluctuation cycle (c) corresponds to different stages of the unsteady flame evolution as demonstrated by OH PLIF images (d-j). The intensity scale and the position of coaxial injector is shown on image (d). This particular data set is from a $\mathrm{H}_{2} / \mathrm{O}_{2}$ case at $\phi=0.2$.

To explore the dependence of combustion instabilities in a coaxial configuration on the fuel used, experiments were conducted using methane instead of hydrogen. Initially, tests were conducted within a similar range of equivalence ratios and chamber pressures as considered in the $\mathrm{H}_{2} / \mathrm{O}_{2}$ cases. For most $\mathrm{CH}_{4} / \mathrm{O}_{2}$ cases, the inner stream Reynolds number $R e_{i}$ varies from 14,000 to 60,000 and the outer stream Reynolds number $R e_{o}$ varies from 500 to 5,000 . Fuel-to-oxidizer velocity differences $\Delta v$ range from $-38 \mathrm{~m} / \mathrm{s}$ to $-9 \mathrm{~m} / \mathrm{s}$. 


\section{Instability in $\mathrm{H}_{2} / \mathrm{O}_{2}$ flames}

Experiments with the $\mathrm{H}_{2} / \mathrm{O}_{2}$ configuration at a mass flow rate of $1 \mathrm{~g} / \mathrm{s}$ resulted in chamber pressures just slightly over atmospheric (insufficient for the nozzle to choked). Under certain conditions of operations, a self-sustained flame instability was observed. ${ }^{6}$ These unstable flames are associated with a periodic pressure oscillation in the combustion chamber with a (root-mean-square) amplitude in the range of $1-3 \%$ of the mean value. Despite the small amplitude of pressure fluctuations, the global structure of the flame was drastically changed. The overall characteristics of the unsteady $\mathrm{H}_{2} / \mathrm{O}_{2}$ flame, such as its instantaneous structure, have been qualitatively described initially in one of our previous studies. ${ }^{6}$ Here we re-evaluate some of our initial observations where we study in more details the correlation between the unsteady flame characteristics, the pressure field, and the flame morphology.

To summarize our initial observations, ${ }^{6}$ under unsteady conditions the flame was observed to be shorter and broader as compared to the stable, elongated and orderly structure of the steady case. In the high-speed chemiluminescence images, the flame was observed to pulsate, generating a vortex-ring like structure, and thus creating a strong ejection of fuel/oxidizer mixture that burned out. The flame then nearly extinguished, only to subsequently reignite and repeat the entire cycle again. OH PLIF imaging was used to investigate the instantaneous planar flame structure. Figure 3 shows a set of OH PLIF images demonstrating the stages of the unsteady flame evolution cycle. These images also show the presence of multiple flame fronts. The inner reaction layer is associated with the $\mathrm{H}_{2} / \mathrm{O}_{2}$ boundary and the outer is associated with the $\mathrm{H}_{2}$ stream and the oxygen-rich outer recirculation zones formed by the post-combustion gases of the inner flame.

\section{A. Combustion chamber pressure fluctuations}

Figure 3a shows the pressure variation during the course of a typical (near ambient pressure) unsteady run for operation at a global equivalence ratio of $\phi=0.2$. The first 2.5 seconds of the run are in the ignition phase, where the premixed pilot first ignites the coaxial jet, and the coaxial flame stabilizes; the following 2 seconds is a transient time where the coaxial flame re-stabilizes after the premixed pilot is shut down. After the initial startup transients, the pressure remains nearly constant and data from this constant portion, typically between the $6 \mathrm{~s}$ and $12 \mathrm{~s}$ marks, is used for analysis.

Figure $3 \mathrm{~b}$ shows an enlarged time series of the pressure trace measured by transducer A (see Figure 2) and demonstrates the existence of a periodic pressure oscillation in the combustion chamber. The nearly harmonic variation suggests the existence of a well-defined pulsing frequency (of order $1 \mathrm{kHz}$ ) with a peakto-peak amplitude of $0.1 \mathrm{~atm}$ modulated at a lower frequency (of order $100 \mathrm{~Hz}$ ). The amplitude of the modulation is only a fraction (approximately $1 / 5$ ) of the amplitude of the high-frequency pulsing frequency. The existence of a series of frequencies is quantified subsequently when the power density spectra of pressure time-history traces are further analyzed. The fluctuation amplitude in the chamber increases with increasing global equivalence ratio, from $\sim 1.5 \%$ at $\phi=0.1$ to $\sim 2.7 \%$ at $\phi=0.3$. This periodic pressure fluctuation, although of relatively small amplitude, strongly affects the instantaneous flame structure in ways described by the OH PLIF series of Figure 3d-j constructed by assembling uncorrelated instantaneous OH PLIF images taken at different phases of a characteristic pressure oscillation period (Figure 3c). We will return to a discussion of the periodic flame changes further below.

For global equivalence ratios larger than 0.3 , the flames visually appear to be steady. A low-amplitude, low frequency fluctuation $(\sim 88 \mathrm{~Hz})$ is observed, but it is not significant enough to alter the flame structure that appears steady. A later section discusses the limits of instability in terms of equivalence ratios.

For these unsteady cases, comparison between the pressure time-histories taken by transducers A and B (refer to Figure 2) reveals that there is a phase difference of about half a cycle between them, as shown in Figure 4; this difference remains constant throughout the run. For steady cases, there is no phase difference between what measured by the two transducers.

During some portions of the pressure fluctuation time-history, the pressure fluctuation exhibits "double peaks" as shown in Figure 5. The frequency of occurrence of these double peaks decreases with an increase in equivalence ratio. Almost $50 \%$ of the cycles for the $\phi=0.1$ case exhibit these double peaks in the cycle and they are almost non-existent in the $\phi=0.3$ case. Furthermore, the appearance of this double peaked structure in the pressure cycle is associated with the falling portion of the low-frequency modulation cycle

only. Subsequently, we will demonstrate through OH PLIF imaging that this double peak in the pressure trace is associated with a modification of the instantaneous flame structure. 


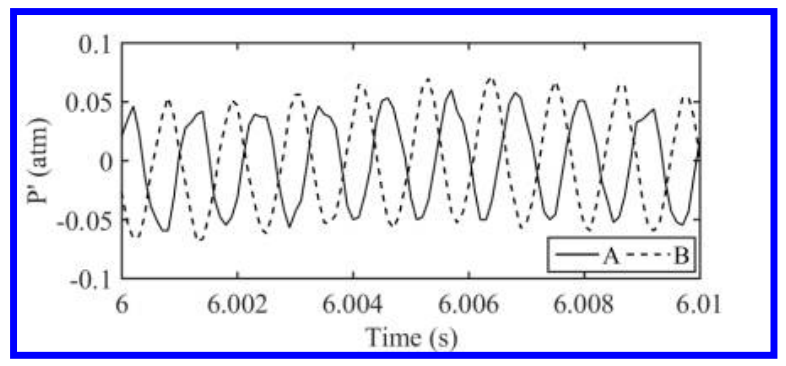

Figure 4. Phase difference between time-histories of transducers A and B

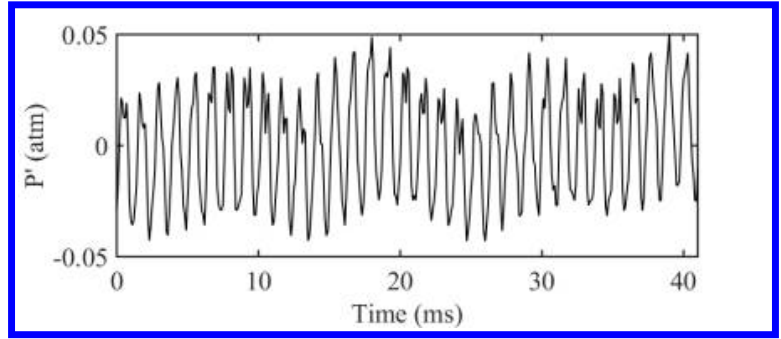

Figure 5. Pressure trace for a $\phi=0.1 \mathbf{H}_{2} / \mathrm{O}_{2}$ case showing the presence of double peaks in the pressure oscillation cycle.

\section{B. Fuel/oxidizer feed lines pressure fluctuations}

Comparison between pressure measurements simultaneously taken in the combustion chamber (transducer A) and within the fuel plenum or oxidizer feed line (transducer C and D, respectively), shows that for unsteady cases the amplitude of the high-frequency pressure oscillation is significantly decreased in the fuel plenum (RMS fluctuation from $2.5 \%$ in the combustion chamber to $\sim 0.6 \%$ in the fuel plenum for the $\phi=0.2$ case), while the corresponding amplitude of the low-frequency modulation remains nearly the same to that in the combustion chamber. Furthermore, the pressure traces indicate that the high-frequency pressure oscillation in the combustion chamber and high-frequency oscillation in the fuel plenum have a phase difference of about $0.7 \mathrm{~ms}$ for both the $\phi=0.1$ and 0.2 cases.

On the contrary, the amplitude of the high-frequency pressure oscillation is increased in the oxidizer feed line relative to that in the combustion chamber. For the $\phi=0.1$ case, the change is about $6 \%$ and for the $\phi=0.2$ case, the change is up to $40 \%$ (from $2.5 \%$ to $3.5 \%$ ), while the amplitude of the low-frequency modulation remains nearly the same. The phase difference remains equal to about $0.7 \mathrm{~ms}$. This suggests that there could be a coupling between the acoustics of the fuel plenum and those of the oxidizer feed line that drive and modulate the high-frequency pressure fluctuation in the combustion chamber.

\section{Flame dynamics}

A typical time trace of the frame-integrated chemiluminescence intensity $\left(S_{c}\right)$ collected during an unsteady run is shown in Figure 6a (solid blue line), and it is compared to the corresponding simultaneous time trace of the pressure fluctuation measured at point $\mathrm{A}$ in the combustion chamber (solid black line, offset for clarity). The frame-integrated chemiluminescence intensity time trace was constructed by integrating the chemiluminescence intensity over each image frame of the time sequence. Comparison of the simultaneous pressure and chemiluminescence time traces indicates that the flame chemiluminescence emission (and thus the flame) responds to the high frequency harmonic pressure fluctuation observed in the combustion chamber at the same frequency (near $1 \mathrm{kHz}$ ), but with a time delay that varies in time. In addition, the chemiluminescence drops to zero during portions of the cycle, which indicates that the flame goes through periodic extinction/ignition cycles at a frequency equal to the pressure fluctuation frequency. Furthermore, the amplitude of the chemiluminescence fluctuation is also modulated by the same low frequency component of the pressure trace to the extent that the flame almost completely extinguishes throughout high frequency cycles during a portion of the low frequency modulation cycle (see near time $6.005 \mathrm{~s}, 6.017 \mathrm{~s}$, etc in Figure 6a). Qualitatively speaking, for the case represented in Figure 6, the low frequency modulation of the 


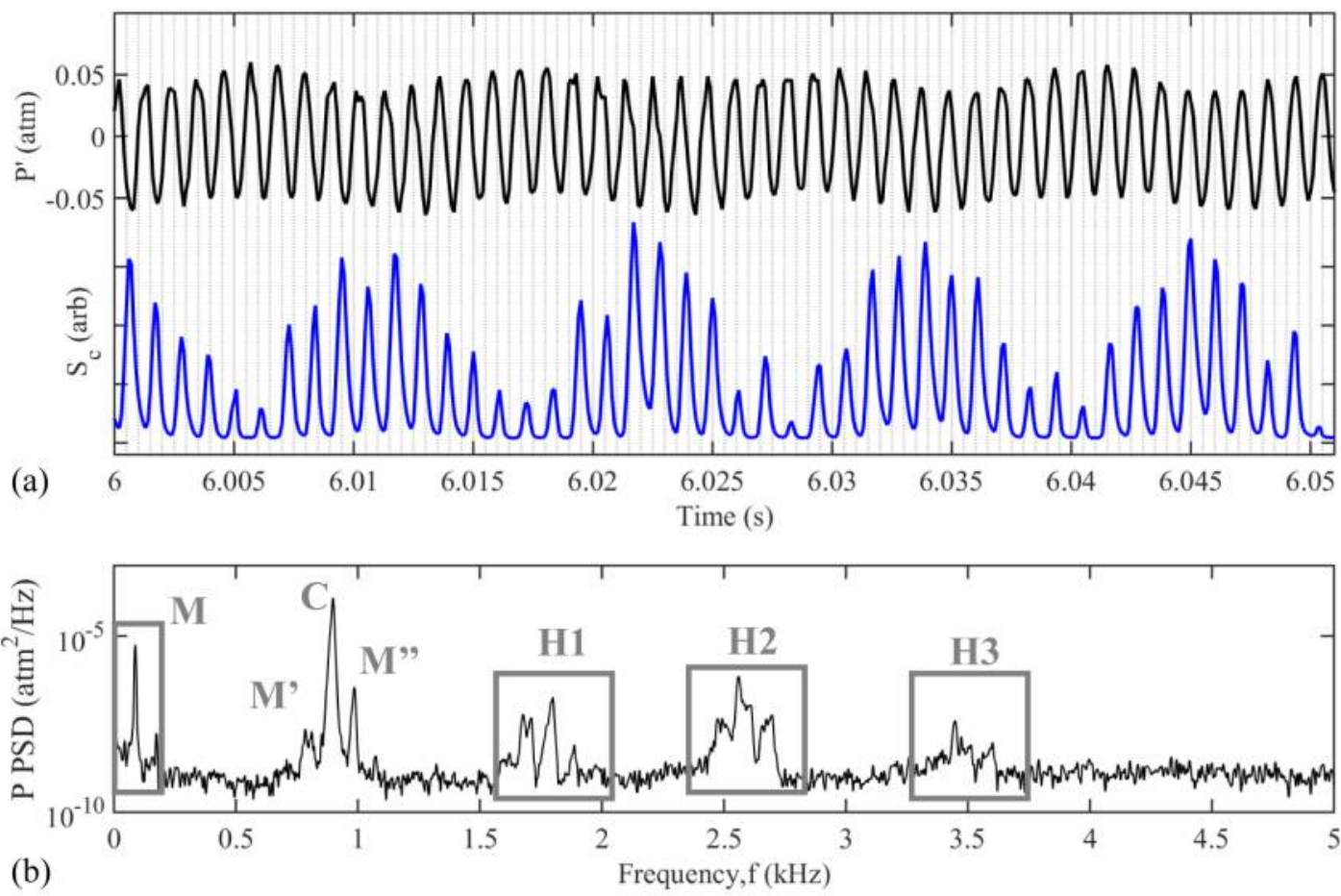

(b)

(c)

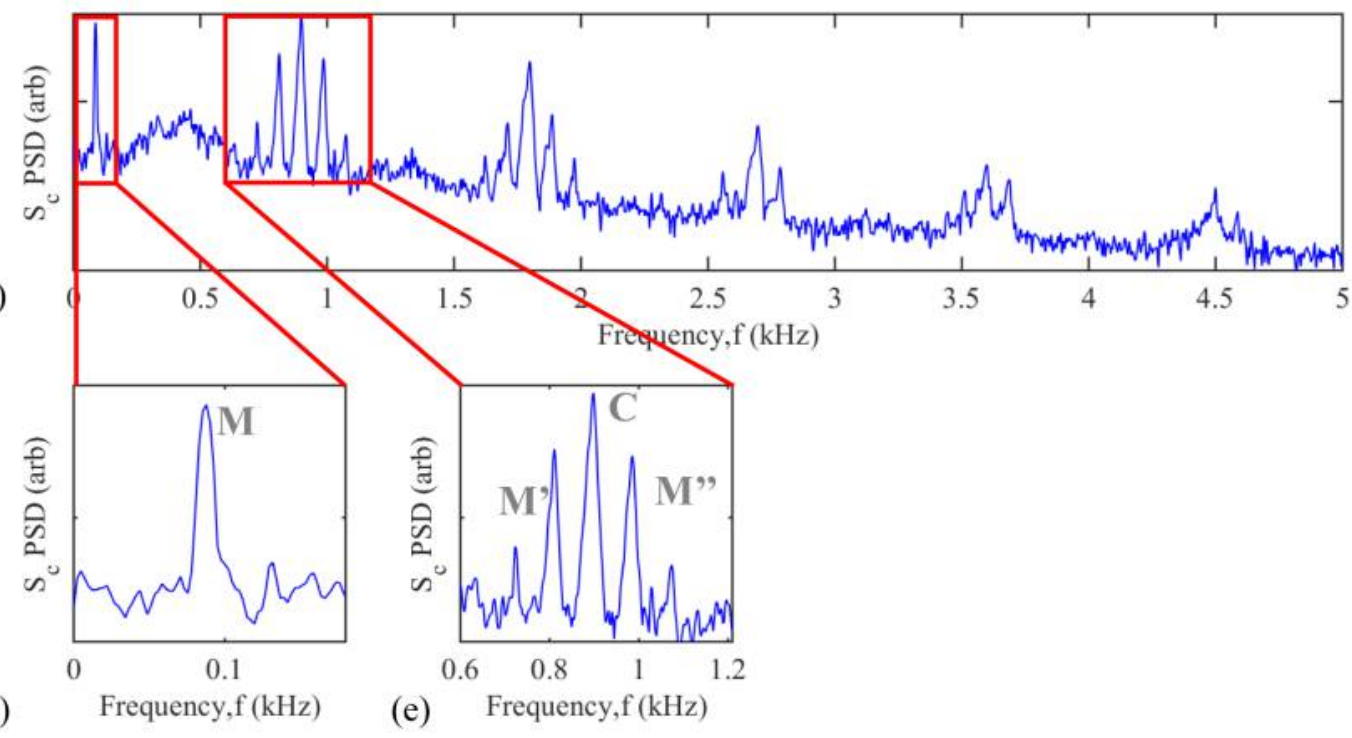

Figure 6. Integrated chemiluminescence data (solid blue line) shows the presence of low and high frequency fluctuations (a) and is compared to the fluctuations in pressure (solid black line). Power Spectral Density (PSD) of pressure (b) and chemiluminescence intensity (c) variation. Insets (d) and (e) are enlarged views of the low and high frequency regions of the PSD of chemiluminescence intensity. These fluctuation time histories and PSDs are for the same data sat presented in Figure 3

combustion pressure change is nearly $180^{\circ}$ out of phase with the chemiluminescence intensity modulation.

The dominant frequencies in both pressure and chemiluminescence time traces were extracted by computing their power density spectrum. The resulting traces are shown in Figure $6 \mathrm{~b}$ and $6 \mathrm{c}$. The heights of 


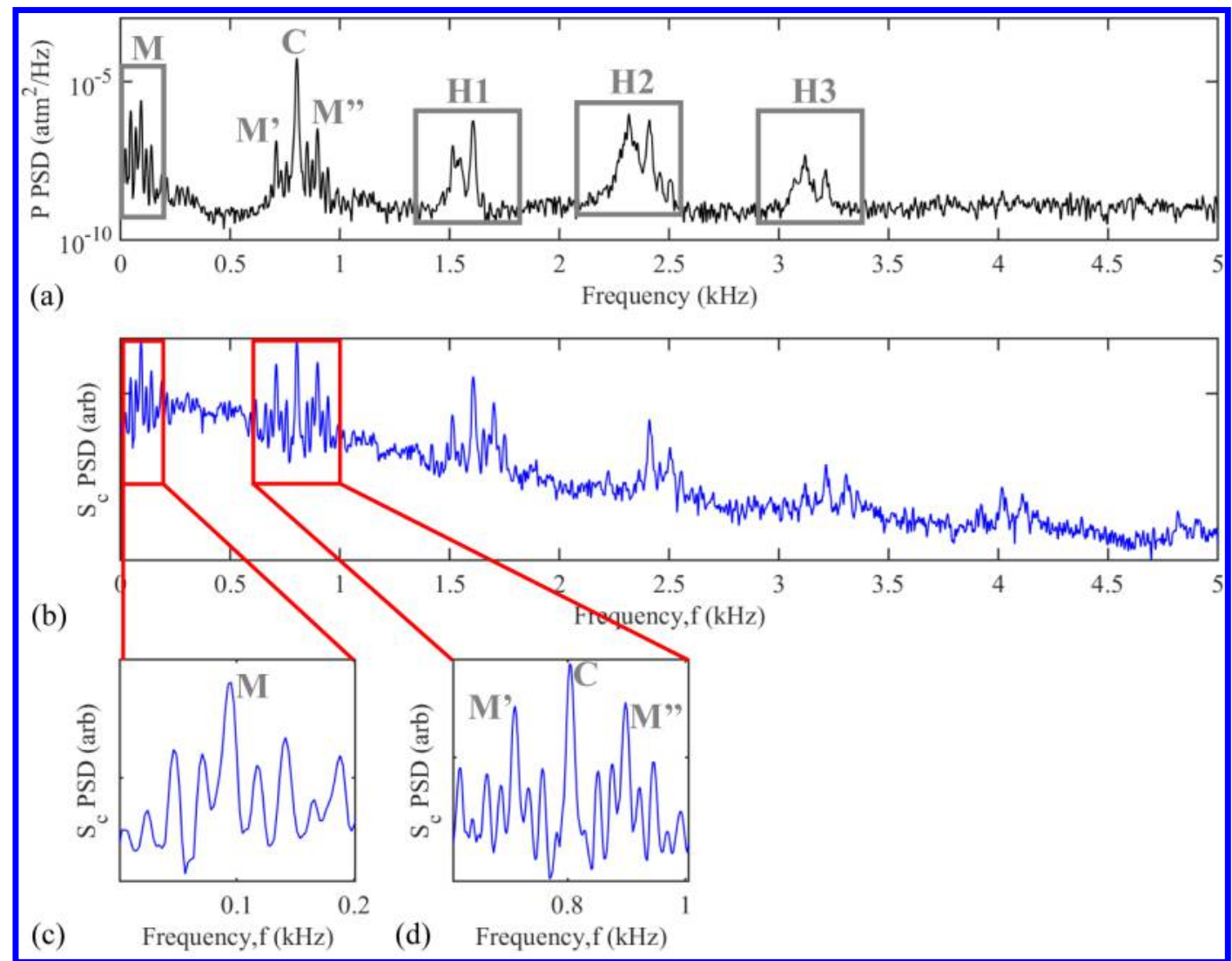

Figure 7. PSD of pressure (a) and chemiluminescence (b) intensity variation for a $\phi=0.1$ case. Insets (c) and (d) are enlarged views of the low and high frequency regions of the PSD of chemiluminescence intensity.

the peaks depict the relative amplitude of the fluctuations at different frequencies shown on the horizontal axis.

Even though both pressure and chemiluminescence traces exhibit the same dominant frequencies, the phase difference between the two traces seems to vary throughout the course of a run. This can be observed in Figure $6 \mathrm{~b}$ where the traces begin with a peak of one corresponding with a trough of the other and end with peaks almost aligned. A relative change in the phase (both increasing and decreasing) between the two traces is observed throughout the run, though no consistent trend is apparent. If the higher frequency fluctuations are neglected and only the lower frequency components of both pressure and chemiluminescence traces are considered, a distinct correlation (either positive or negative) between the two is observed in some cases, but the trend does not stay the same over multiple runs of the same case.

\section{Pressure fluctuation amplitude modulation and frequency content}

The pressure traces of Figure 3b and Figure $6 \mathrm{a}$ for the $\phi=0.2$ case have suggested that the high-frequency pressure fluctuation is modulated by a lower frequency component. Low-frequency modulation of the highfrequency fluctuations in the chemiluminescence intensity is also observed (see Figure 6a) where the intensity of the flame periodically diminishes, to nearly globally extinguish for certain high-frequency cycles. Amplitude modulation of both pressure and flame chemiluminescence can be observed more clearly in the corresponding power spectra of Figure 6b and 6c: two sidebands (near $820 \mathrm{~Hz}$ and $980 \mathrm{~Hz}$ ) are observed around the main high-frequency ("carrier") component (near $900 \mathrm{~Hz}$ in Figure 6e), which correspond to the amplitude modulation frequency observed at about $90 \mathrm{~Hz}$ (Figure 6d). The overall time trace signal is then the summation of the low frequencies and the amplitude modulated higher frequencies. A similar behavior is also observed for the $\phi=0.1$ case; the corresponding power spectra of the pressure and chemiluminescence intensity traces are shown in Figure $7 \mathrm{a}$ and $7 \mathrm{~b}$ respectively.

Although the power spectra indicate two main frequency groups, they also identify a range of additional 
frequency components, some of which are found to vary with equivalence ratio. Upon closer inspection of the available data on unsteady cases, the low-frequency modulation component appears to be composed of a set of modes (see group M in Figure 6 and Figure 7) centered around a dominant (modulation) mode at $88 \mathrm{~Hz}$; the exact structure of this set of modes depends on the equivalence ratio. At the lowest equivalence ratio, several such modes grouped in the $0-200 \mathrm{~Hz}$ range and spaced by about $24 \mathrm{~Hz}$ are observed (Figure $7 \mathrm{c}$ ). Most of these modes are observed to modulate the high-frequency (carrier, C in Figure 6 and Figure 7) fluctuation component (see the complex structure of the frequency grouping M' and M" to the side of the carrier mode $\mathrm{C}$ in Figure 6 and Figure 7). As the equivalence ratio is increased, there are less modes in the group, while the dominant mode at $88 \mathrm{~Hz}$ remains unaltered (in frequency value and peak magnitude relative to peak of the high frequency mode $\mathrm{C}$ ). In addition, the dominant modulation mode at $88 \mathrm{~Hz}$ is also observed to exist at higher equivalence ratios where the flame is found to be visually steady. Thus, the modulation component might not be driven by a strong coupling with the unsteady combustion.

The high-frequency fluctuation mode ( $\mathrm{C}$ in Figure) is observed to exist for cases with an equivalence ratio less than 0.3 ; above this value the flame is a steady, attached, flame. ${ }^{6}$ However, the numerical value of this mode (and its harmonics, see mode groups H1, H2 and H3 in Figure 6 and Figure 7) is found to increase linearly with equivalence ratio (from $\sim 800 \mathrm{~Hz}$ at $\phi=0.1$, to $\sim 1 \mathrm{kHz}$ at $\phi=0.3$ ), and to inversely depend on the combustion chamber length, leading to the conclusion these are thermoacoustic in nature. ${ }^{6}$ The lowfrequency modes (on the order of $100 \mathrm{~Hz}$ ) were seen to be independent of combustion chamber length.

In addition to the dominant low- and high-frequency groups, the power spectra also captures a set of additional modes at intermediate frequencies whose origin is not understood yet. Looking at the power spectrum (Figure 6c), there are some modes in the $400-600 \mathrm{~Hz}$ frequency range. These modes do not fall in the category of either the low-frequency group or the modulated high-frequency component. Preliminary calculations indicate that the Helmholtz frequency of the fuel plenum falls in this range; thus we attribute the presence of this component to a Helmoltz resonance of the fuel plenum. Further analysis is however required to verify this hypothesis.

\section{E. Flame structure changes over the pressure fluctuation cycle}

Different stages of the flame evolution, as visualized using OH PLIF imaging, appear to correlate very well to different phases of the pressure fluctuation cycle as shown by representative images in Figure 3d-j. The flame reignites when the pressure is at a minimum and reaches its peak (the tallest stage of the flame where the multiple shear layers still distinctly visible, as in Figure 3f) just before the peak of the pressure cycle. After the peak, the shear layers begin to collapse and the flame extinguishes completely by the time the pressure reaches its lowest value again.

The flame behavior is somewhat different when double peaks are present in the pressure time history. It follows the same stages as shown in Figure 3d-j until it reaches the first pressure peak. Beyond this, the extinction phase starts and no flame is observed beyond the intermediate trough. Re-ignition only happens when the pressure reaches its lowest point.

\section{Characteristics of unsteady $\mathrm{CH}_{4} / \mathrm{O}_{2}$ flames}

There are many morphological changes in the structure of the unsteady flame when $\mathrm{CH}_{4}$ is used as a fuel instead of $\mathrm{H}_{2}$. The $\mathrm{CH}_{4} / \mathrm{O}_{2}$ cases do not exhibit the same mushroom like structure seen in Figure 3, though the inner and outer shear layers still exist (Figure 8). The instability limit, discussed in the next section, is also different in case of $\mathrm{CH}_{4} / \mathrm{O}_{2}$ cases, with flames being unsteady until higher equivalence ratios when compared to $\mathrm{H}_{2} / \mathrm{O}_{2}$ flames.

\section{A. Combustion chamber pressure fluctuations}

Figure $8 \mathrm{a}$ shows a pressure time-history during a typical run of a low pressure methane case $(\dot{m}=1 \mathrm{~g} / \mathrm{s})$ at $\phi=0.5$. Neglecting the first 4 seconds of startup transients and focusing on the established flame (see Figure $8 \mathrm{~b}$ ), we observe the existence of various phases during the temporal evolution of the flowfield .

After the initial startup transients (first $2 \mathrm{~s}$ ), there is an initial region where pressure remains relatively steady except for the presence of periodic pressure 'spikes' (Figure 8a and Region I in Figure 8b). In this region, the flame is attached to the injector rim, but only the inner shear layer is present (see the simultaneous $\mathrm{OH} / \mathrm{CH}_{2} \mathrm{O}$ PLIF image of Figure $8 \mathrm{c}$ that demonstrates a typical $\mathrm{OH} / \mathrm{CH}_{2} \mathrm{O}$ distribution during this phase). 


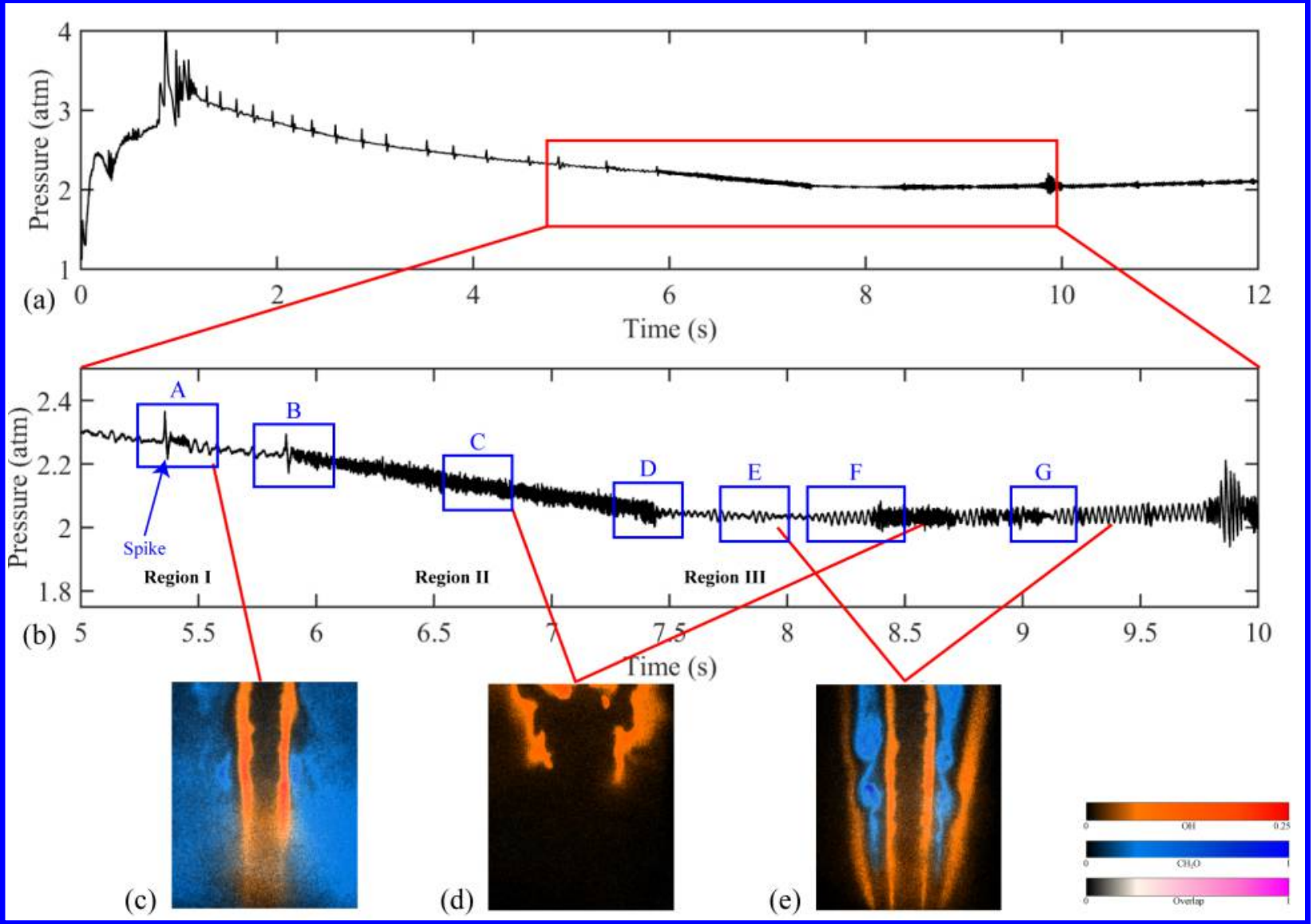

Figure 8. A typical pressure trace of an unsteady $\mathrm{CH}_{4} / \mathrm{O}_{2}$ flame is shown in (a). An enlarged view (b) shows variations in pressure at different points in time during the run. Regions A-G are shown in detail in Figure 9. Combined $\mathrm{OH}$ (orange-red) and $\mathrm{CH}_{2} \mathrm{O}$ (blue) PLIF images (c-f) show representative flame structures and formaldehyde distribution during different stages of the pressure trace. The bottom of the every PLIF image represents the position of the injector face. All colorbars represent the relative intensity of the signal. The bottom colorbar (pink) represents the overlap between the $\mathrm{OH}$ and $\mathrm{CH}_{2} \mathrm{O}$ signals and the intensity of the colorbar represents the amounts of both present. This particular data set if from a $\mathrm{CH}_{4} / \mathrm{O}_{2}$ case at $\phi=0.5$.

In addition, there is a strong formaldehyde region outside the shear layer, especially within the lateral recirculation region. This suggests that not all of the fuel is consumed by the inner shear layer and, although the system is globally fuel lean and oxidizer-rich lateral recirculation regions should be expected, an outer reacting shear layer between fuel stream and the recirculation region cannot be established, unlike what is observed in some of the $\mathrm{H}_{2} / \mathrm{O}_{2}$ cases. Periodically, the flame lifts off momentarily but reattaches immediately; this transient process is associated with the series of pressure spikes observed in the early portion of the run (Figure 8a).

After this initial phase, starting at about $6 \mathrm{~s}$ and terminating at about $7.5 \mathrm{~s}$, a phase with high frequency pressure fluctuations is observed (Region II in Figure 8b). The fluctuation frequency in this portion is about $1 \mathrm{kHz}$. In this region, the flame is lifted and the position of its base is fluctuating. The flame structure as visualized by OH PLIF (see Figure 8d) is organized in a complex, convoluted and broadened region. No detectable levels of formaldehyde are present in the lifted region, except for in some instances where it tends to overlap with the OH PLIF signal. We refer to this phase as "lifted flame, unstable combustion mode".

This second phase is followed by a third phase characterized by lower frequency $(\sim 30-40 \mathrm{~Hz})$ pressure oscillations between $7.5 \mathrm{~s}$ and $8.5 \mathrm{~s}$ (Region III in Figure 8b). In this phase, the flame reattaches (see Figure 8e). As inferred from the $\mathrm{OH}$ distribution, the flame is now composed of an inner and an outer reacting shear layer that encompass the intermediate region where fuel begins to break down and oxidize, as indicated by the presence of significant amount of formaldehyde that marks the intermediate shear layer. Although the flame structure remains similar to what is shown in Figure 8e for the most part during this 
phase, a low-frequency pressure fluctuation of significant amplitude does exist. This fluctuation, however, is not sufficient to significantly alter the flame structure (at least in the injector near-field where the flame is visible). Thus, in practice, the flame can be considered to be stable, or at least quiet. We refer to this phase as "attached flame, quiet combustion mode".

After the third phase, the flame dynamics evolves through a series of changes between the unstable and the quiet mode. Once the flame enters one of the two modes (as identified by the pressure time history profile), the flame structure remains qualitatively similar to what was described for the two modes and represented by Figures 8d and 8e. Inspection of the chemiluminescence movies also confirms that the flame undergoes periodic transition between the two modes. Similar dynamics and trends are observed for $\phi=0.6$ and in some instances for $\phi=0.7$ cases, which tends to operate more in the quiet mode than in the unstable mode. Beyond a $\phi=0.7$, the flame mostly remains stable.

The transitions between the various combustion modes identified above and shown in Figure 8b are an important aspect of the methane flame dynamics and are not observed in the hydrogen runs. Some specific characteristic events are identified by labels A through G in Figure 8b (also shown in an enlarged scale in Figure 9), and they are taken as representative of critical flame dynamics as the system transitions between different modes. The transition event of Figure 9(a) (event A in Figure 8b) corresponds to the case where the flame rapidly lifts off the injector face but reattaches immediately. As mentioned earlier in the section, this event is associated with the pressure spike near $5.35 \mathrm{~s}$. Following the pressure spike, the pressure exhibits rapid (high-frequency, near $1.2 \mathrm{kHz}$ ) variation of small amplitude superimposed on a moderate frequency (near $180 \mathrm{~Hz}$ ), moderate amplitude modulation, both of which die off after a few cycles between $5.4 \mathrm{~s}$ and $5.45 \mathrm{~s}$. After this event, the pressure trace varies harmonically at some low frequency (near $20 \mathrm{~Hz}$ ) but fairly significant amplitude. As discussed earlier, the flame appears stable for the most part.

Figure 9(b) (event B in Figure 8b) shows a similar event to that of Figure 9(a), with the only difference that the modulated high-frequency pressure fluctuation after the initial pressure spike does not die off, but reaches a limit cycle behavior that persists between $6 \mathrm{~s}$ and $7.2 \mathrm{~s}$. This limit cycle is shown in detail in Figure 9(c) (event $\mathrm{C}$ in Figure 8b). It is composed of a moderate frequency, moderate amplitude modulation of the high frequency component, and the flame structure remains similar to what shown earlier in Figure 8d. It is interesting to note here that unlike the hydrogen cases, the high frequency component has a significantly lower amplitude than the moderate frequency component.

Figure 9(d) (event D in Figure 8b) shows the pressure time history as the flame undergoes the transition from the unstable to the quiet mode. During the transition, the magnitude of the high frequency component gradually decays until it disappear (at $7.47 \mathrm{~s}$ ), while the modulation component rapidly transitions (within one cycle) from moderate frequencies $(\sim 180 \mathrm{~Hz})$ to low frequencies $(\sim 20 \mathrm{~Hz})$. During the quiet combustion mode portion, pressure varies at low frequencies but with a significant amplitude variation. This is shown in the event of Figure 9(e) (event E in Figure 8b). However, the flame remains fairly stationary with a flame structure consistently similar to what was shown in Figure 8e. During the quiet mode portion, the amplitude of the pressure variation tends to undergo amplification and attenuation phases that may result in a return to an unstable combustion mode. This is, for example, observed in the event of Figure 9(f) (event F in Figure 8b) where the low frequency pressure variation grows in amplitude until the flame suddenly transitions to the unstable mode where the pressure variation returns to be composed of a high-frequency component of small amplitude modulated by a moderate-amplitude, moderate-frequency component. Finally, Figure $9(\mathrm{~g})$ (event G Figure $8 \mathrm{~b}$ ) shows a detailed view of the pressure fluctuation as the flame rapidly transitions back and forth between the unstable and quiet modes.

For equivalence ratios greater than 0.7 , the $\mathrm{CH}_{4} / \mathrm{O}_{2}$ flame remains steady and attached to the injector rim throughout the run (after the initial startup transients). Figure 10 shows a typical pressure time-history of a steady methane flame. During the initial transients (from start to about $4 \mathrm{~s})$, a low frequency $(\sim 40$ $\mathrm{Hz}$ ) fluctuation with a significant amplitude is observed in the pressure trace (event A in Figure 10b). This portion of the run is associated with a flame that is composed of an inner and an outer reacting shear layer as visualized by OH PLIF, surrounding an intermediate layer with fuel breaking down, as indicated to by the presence of formaldehyde (Figure 10c).

Visually, the flame is very similar to that described in Region III of unsteady $\mathrm{CH}_{4} / \mathrm{O}_{2}$ case above and represented by Figure 8e. This region of low frequency fluctuations is followed by pressure spikes (event B in Figure 10b) similar to those observed in the unsteady cases (refer to Figure 9(a)). The spike is associated with the flame momentarily lifting off before reattaching and is followed by moderate-amplitude, moderatefrequency fluctuations. No more than two or three such spikes and the associated liftoff and reattachment 


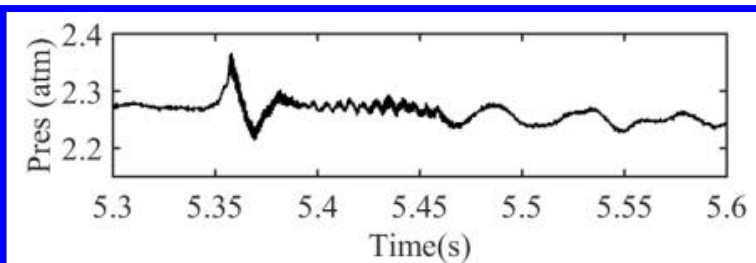

(a)

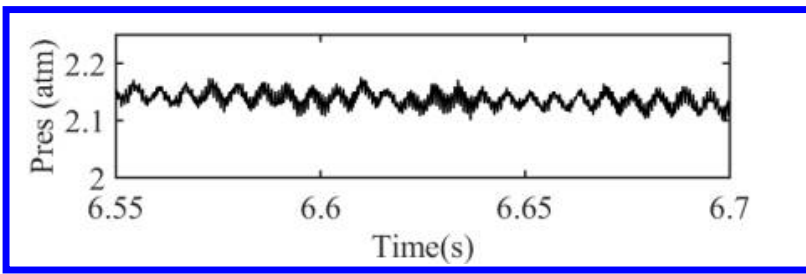

(c)

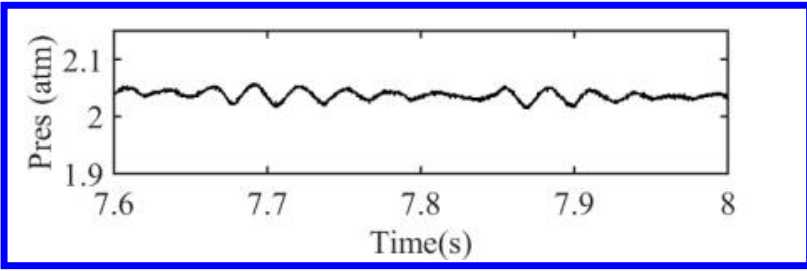

(e)

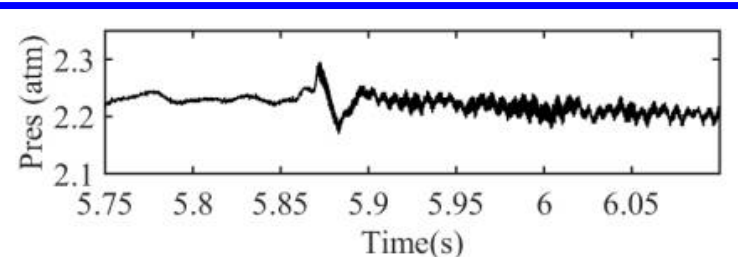

(b)

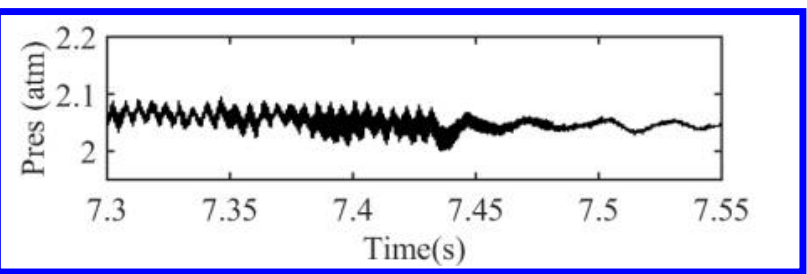

(d)

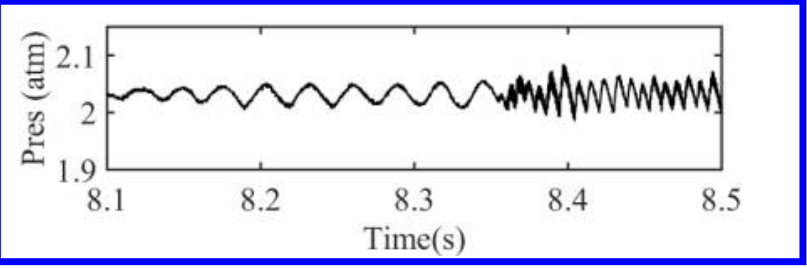

(f)

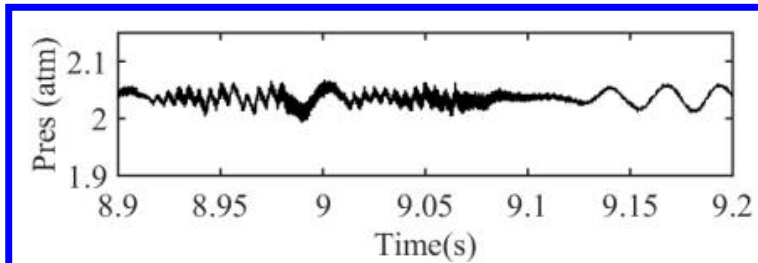

(g)

Figure 9. Detail of the time-history of combustion chamber pressure at point A during different transition phases A though $\mathbf{G}$ of Figure $8 \mathbf{b}\left(\mathbf{C H}_{4} / \mathbf{O}_{2}\right.$ cases at $\left.\phi=0.5\right)$.

events are observed in cases that are considered steady, and all of them occur within the initial transient phase.

As these low frequency oscillations and the accompanying attached flame with both inner and outer shear layers are observed only during the initial transient phase, they are thought to be associated with the pilot flame ignition system augmenting the combustion of fuel and oxidizer mixture in the outer layer.

Towards the end of the transient phase, a pressure spike followed by high-frequency, moderate-amplitude fluctuations gives way to lower amplitude, almost steady oscillations (event C in Figure 10b). The flame during this phase, which lasts through the rest of the run, is attached to the injector rim and has a reacting inner shear layer. The outer shear layer is absent and there is a significant formaldehyde signal in the lateral recirculation zone. No coherent structure is apparent in the pressure time-history and a power spectrum does not reveal any organized frequencies either.

\section{B. Chemiluminescence and the flame structure}

For unsteady methane cases, the power spectrum obtained from chemiluminescence images does not show the same dominant high frequencies as that from the pressure spectrum. Figure 11 shows a portion of the timehistory from Region II of the unsteady case discussed in the previous section and represented in Figure 8. The flame is lifted and the location of flame base oscillates with time. The troughs in the chemiluminescence intensity time-history represent instances when the flame was lifted beyond the imaging window, resulting in a decrease in overall captured intensity. It can be deduced from comparing the pressure and chemiluminescence 


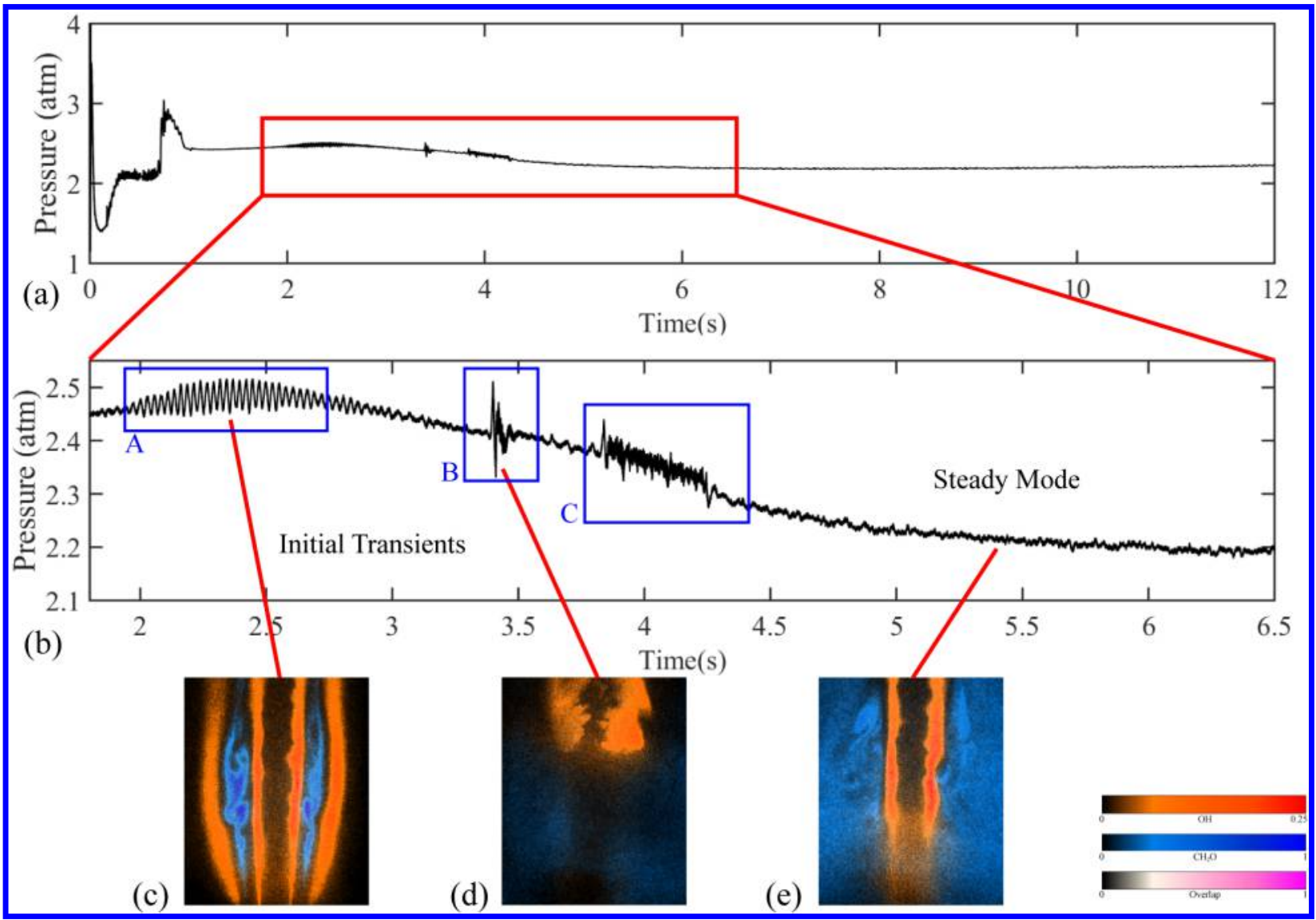

Figure 10. A typical pressure trace of a steady $\mathrm{CH}_{4} / \mathrm{O}_{2}$ flame is shown in (a). An enlarged view (b) shows variations in pressure at different points in time during the run. Combined $\mathrm{OH}$ (orange-red) and $\mathrm{CH}_{2} \mathrm{O}$ (blue) PLIF images (c-f) show representative flame structures and formaldehyde distribution during different stages of the pressure trace. The images are processed similar to others in Figure 8 and the colorbars have the same meaning. This particular data set if from a $\mathrm{CH}_{4} / \mathrm{O}_{2}$ case at $\phi=0.8$.

traces and looking at the spectra that the unsteady flame does not extinguish at the same high frequency of the pressure fluctuations, unlike the $\mathrm{H}_{2} / \mathrm{O}_{2}$ cases. Also, the flame base dynamics seem to be associated with the moderate-amplitude, moderate-frequency mode modulating the high-frequency pressure fluctuations. For cases that are steady, the power spectra do not show the presence of any organized frequency modes.

\section{Comparison of instability limits}

To study the dependence of onset of instability on fuel-oxidizer composition, a critical equivalence ratio $\phi_{c r}$ was defined. Cases with equivalence ratios lower than $\phi_{c r}$ were unsteady while those above it were steady. A steady flame for $\mathrm{H}_{2} / \mathrm{O}_{2}$ cases is defined to be one which does not exhibit periodic cycles with extinction and reignition. In the case of $\mathrm{CH}_{4} / \mathrm{O}_{2}$ flames, a steady flame is defined as one which does not undergo cycles of lift-off and reattachment and maintains a constant flame structure throughout, without switching between one and two shear layers morphology.

For low mass flow rate $\mathrm{H}_{2} / \mathrm{O}_{2}$ cases, $\phi_{c r}$ is observed to be 0.4 while for higher mass flow cases (i.e., higher combustion chamber pressure), ${ }^{5}$ it shifts to 0.6. Figure 12 shows how the nature of the flame changes depending on equivalence ratio and pressure. As can be seen from the figure, $\phi_{c r}$ increases with an increase in pressure. $\phi_{c r}$ could shift further to higher values, even to fuel-rich values as found in actual rocket operations, as pressure increases if the same trend continues. Even with the very limited number of $\mathrm{CH}_{4} / \mathrm{O}_{2}$ results available, it can be seen that the flames are unstable until a much higher $\phi$ as compared to $\mathrm{H}_{2} / \mathrm{O}_{2}$ cases.

As our facility is limited to $10 \mathrm{~atm}$, this is an aspect that cannot be further explored using the current setup. However, more experiments need to be done to populate the plot of Figure 12 completely. If methane 

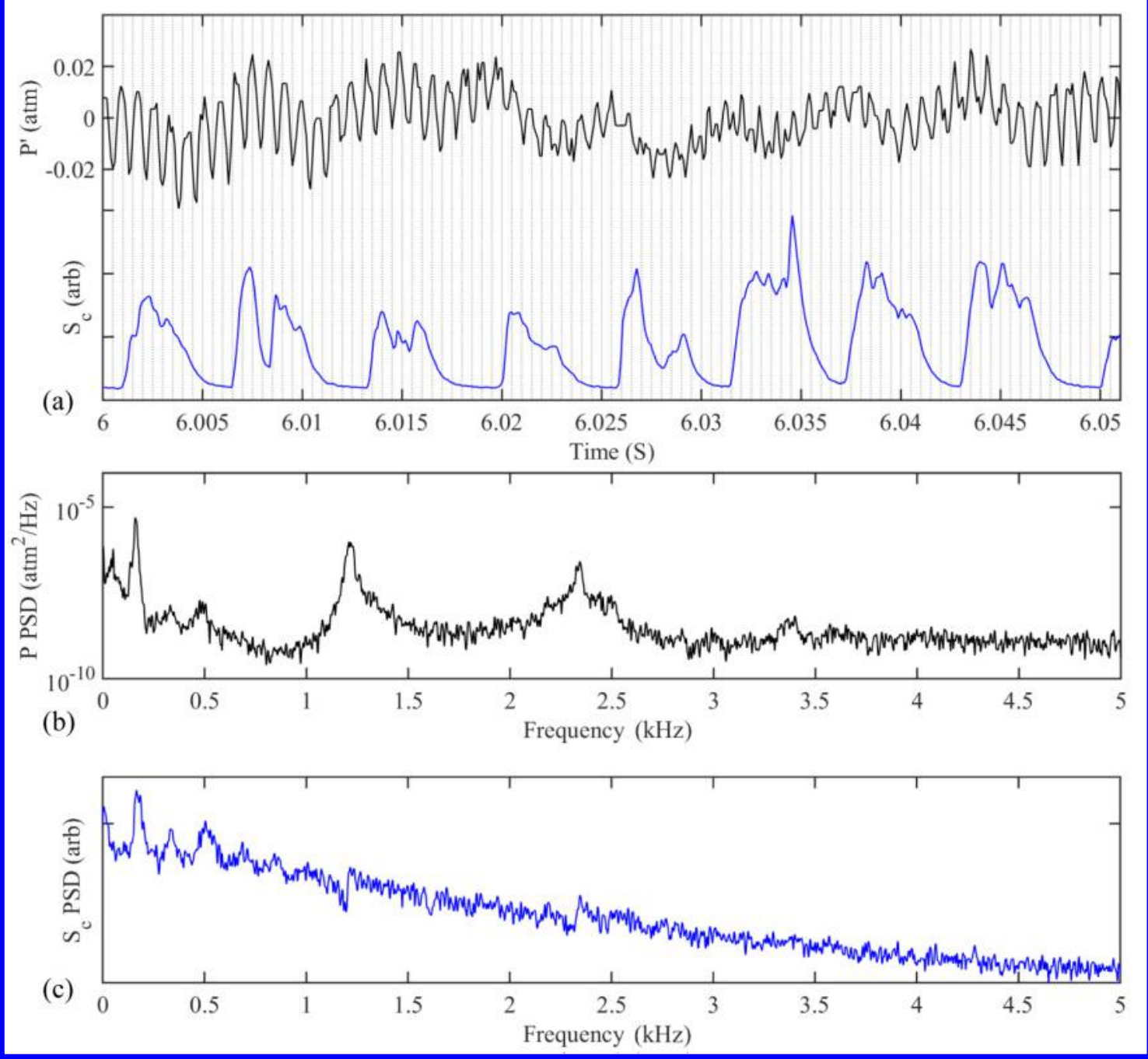

Figure 11. Pressure fluctuations (solid black line) for an unsteady $\mathrm{CH}_{4} / \mathrm{O}_{2}$ case show the presence of moderate and high frequency components and are compared to integrated chemiluminescence data (solid blue line). PSD of pressure and chemiluminescence intensities are shown in (b) and (c) respectively. This data is from Region II of the case discussed in Figure 8.

exhibits a trend similar to hydrogen, instabilities could possibly be observed at near-stoichiometric or even stoichimetric conditions within the limitations of our combustor.

Table 1 summarizes the low pressure cases for both configurations up to the stability limit. In one of our previous works concerning non-reacting mixing experiments, ${ }^{16}$ we found that the (inner-to-outer) momentum flux ratio $J=S R^{2}$ was an important parameter in delineating the steady and unsteady cases. $R=v_{i} / v_{o}$ and $S=\rho_{i} / \rho_{o}$ are the (inner-to-outer) velocity and density ratios respectively. Hydrodynamic instabilities in non-reacting coaxial jets occurred only beyond a $J$ of about 20 in our setup. Instability limit of reacting cases is different than that of the corresponding non-reacting ones and this difference is possible due to the effects of heat release and chemical kinetics.

\section{Current and future experiments}

More cases need to be run to populate Figure 12. This will help in understanding the effect that pressure has on the critical equivalence ratio for both $\mathrm{H}_{2} / \mathrm{O}_{2}$ and $\mathrm{CH}_{4} / \mathrm{O}_{2}$ cases. To explore the coupling between feed lines and the combustion chamber, which could be responsible for the low frequency instabilities and possibly trigger higher frequency instabilities, pressure drops will be introduced upstream of the injector 


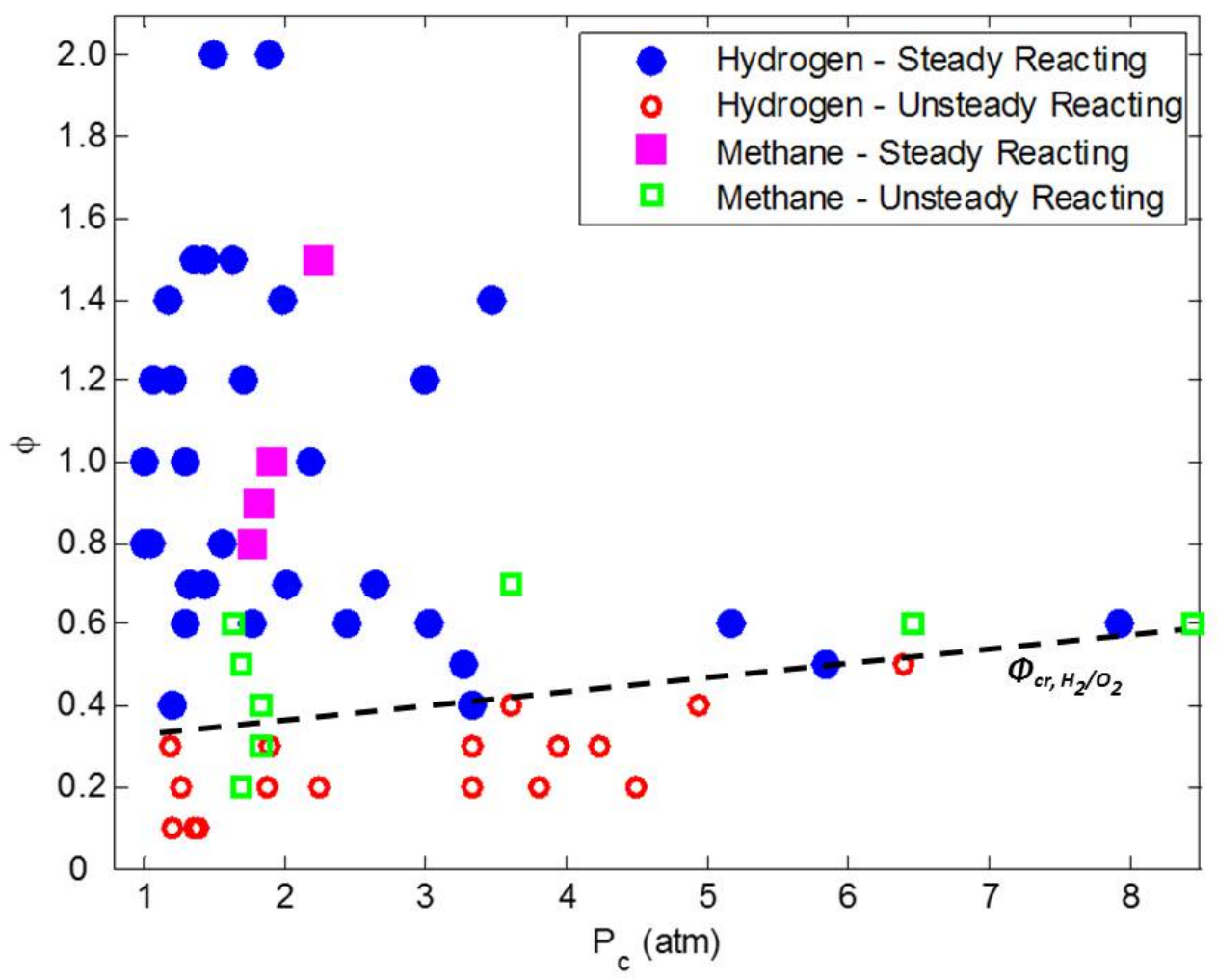

Figure 12. Map showing equivalence ratio and chamber pressure of various steady and unsteady $\mathrm{H}_{2} / \mathrm{O}_{2}$ and $\mathrm{CH}_{4} / \mathrm{O}_{2}$ test cases. Dotted line shows the boundary between steady and unsteady regimes for $\mathrm{H}_{2} / \mathrm{O}_{2}$, defined here as $\phi_{c r}$.

Table 1. Equivalence $(\phi)$ and inner-to-outer momentum flux $(J)$ ratios of low pressure reacting cases $(\dot{m}=1$ $\mathrm{g} / \mathrm{s}) . \mathbf{S}=$ Steady, US=Unsteady.

\begin{tabular}{ccc}
$\phi$ & $J$ & $\mathrm{~S} / \mathrm{US}$ \\
\hline \multicolumn{3}{c}{$\mathrm{H}_{2} / \mathrm{O}_{2}$} \\
\hline 0.1 & 1148 & $\mathrm{US}$ \\
0.2 & 287 & $\mathrm{US}$ \\
0.3 & 128 & $\mathrm{US}$ \\
0.4 & 72 & $\mathrm{~S}$ \\
\hline \multicolumn{3}{c}{$\mathrm{CH}_{4} / \mathrm{O}_{2}$} \\
\hline 0.2 & 571 & $\mathrm{US}$ \\
0.3 & 254 & $\mathrm{US}$ \\
0.4 & 143 & $\mathrm{US}$ \\
0.5 & 91 & $\mathrm{US}$ \\
0.6 & 63 & $\mathrm{US}$ \\
0.7 & 47 & $\mathrm{US}$ \\
0.8 & 36 & $\mathrm{~S}$
\end{tabular}

with the aim to acoustically decouple the combustion chamber from the feed lines. Looking at the instability characteristics of the chamber with these pressure drops might provide an insight into the triggering, sustaining and modulating mechanisms of the instabilities.

Absorption based temperature and pressure measurements, which are currently being developed in the 
group, would help understand the acoustic field inside the chamber much better. Knowing what the acoustic field inside exactly looks like would help in better theoretical estimates.

There is also a possibility of using PIV in the future to visualize the velocity field in the recirculation zone and understanding how it might lead to flame stabilization. Past attempts at performing PIV measurements within the combustion chamber were unsuccessful because of moisture formation. A high speed system or the use of a different tracer might help with that problem.

\section{Conclusions}

Unsteady coaxial $\mathrm{H}_{2} / \mathrm{O}_{2}$ and $\mathrm{CH}_{4} / \mathrm{O}_{2}$ flames were observed under global fuel lean conditions in the Michigan Single Element Injector Facility. Correlations between OH PLIF images and phases of pressure cycle showed that flame extinction begins at a pressure peak, and reignition begins at a pressure trough. No definite correlation was observed between pressure and chemiluminescence fluctuations. By conducting $\mathrm{H}_{2} / \mathrm{O}_{2}$ experiments at higher mass flow rates, and hence higher pressures, it was shown the critical equivalence ratio $\phi_{c r}$, which delineates the transition from unsteady to steady combustion, increases with increase in mass flow rate (and hence chamber pressure).

$\mathrm{CH}_{4} / \mathrm{O}_{2}$ flames showed unsteady combustion at higher equivalence ratios even at lower mass flow rates. This leads to the possibility of observing instabilities at near-stoichiometric or even rich conditions in the chamber at higher pressure conditions. The structure of $\mathrm{CH}_{4} / \mathrm{O}_{2}$ flames was different from what was observed in the $\mathrm{H}_{2} / \mathrm{O}_{2}$ cases, and they undergo multiple cycles of quiet, attached and unsteady, lifted modes. In this way, unsteady $\mathrm{CH}_{4} / \mathrm{O}_{2}$ cases provide an opportunity to observe and evaluate the transition from one combustion mode to another. Understanding what triggers the change might help explain the initiation and evolution of instabilities in the combustion chamber.

\section{Acknowledgments}

The authors would like to thank Dr. Campbell D. Carter, Air Force Research Laboratory, WrightPatterson Air Force Base, OH for lending us an Andor iXon EMCCD and a PI-MAX ICCD. This work was supported by NASA Marshall Space Flight Center under grant no. NNM13AA11G with P. Kevin Tucker as Technical Mentor.

\section{References}

${ }^{1}$ Culick, F. E. C. and Yang, V., "Overview of Combustion Instabilities in Liquid-Propellant Rocket Engines," Liquid Rocket Engine Combustion Instability Progress in Astronautics and Aeronautics, Vol. 169, AIAA, Washington, DC, 1995, pp. $3-37$.

2 Rayleigh, J. W. S., "The Explanation of Certain Acoustical Phenomena," Nature, Vol. 18, No. 319, 1878 , pp. 319-321.

${ }^{3}$ Harrje, D. T. and Reardon, F. H., "Liquid propellant rocket combustion instability," NASA-SP-194, NASA, Washington, DC, 1972 , p. 657.

${ }^{4}$ Crocco, L. and Cheng, S.-I., Theory of Combustion Instability in Liquid Propellant Rocket Motors, AGARDograph, Butterworths Scientific Publications, London, jan 1956.

${ }^{5}$ Dasari, A., White, L. W., and Gamba, M., "Flowfield and Flame Structure in a Laboratory Scale Single Element Combustor under Unsteady Operation," 9th U. S. National Combustion Meeting, Cincinnati, OH, 2015, p. 10.

${ }^{6}$ Dasari, A., White, L. W., and Gamba, M., "Investigation of Instability Mechanisms in a Laboratory Scale GH2/GO2 Combustor," 53rd AIAA Aerospace Sciences Meeting, American Institute of Aeronautics and Astronautics, Kissimmee, FL, 2015, p. 15.

${ }^{7}$ Schumaker, S. A. and Driscoll, J. F., "Mixing properties of coaxial jets with large velocity ratios and large inverse density ratios," Physics of Fluids, Vol. 24, No. 5, 2012.

${ }^{8}$ Schumaker, S. A., An Experimental Investigation of Reacting and Nonreacting Coaxial Jet Mixing in a Laboratory Rocket Engine, Ph.D. thesis, University of Michigan, Ann Arbor, 2009.

${ }^{9}$ Moser, M., Merenich, J., Pal, S., and Santoro, R. J., "OH-radical imaging and velocity field measurements in a gaseous hydrogen/oxygen rocket," 29th Joint Propulsion Conference and Exhibit, Joint Propulsion Conferences, American Institute of Aeronautics and Astronautics, Reston, Virigina, jun 1993.

${ }^{10}$ Santoro, R. J., Pal, S., Woodward, R., and Schaaf, L., "Rocket Testing at University Facilities," 39th Aerospace Sciences Meeting and Exhibit, Aerospace Sciences Meetings, American Institute of Aeronautics and Astronautics, Reno, NV, jan 2001, p. 16.

${ }^{11}$ Hutt, J. and Cramer, J., "Advanced rocket injector development at the Marshall Space Flight Center," Space Programs and Technologies Conference, SPACE Conferences \& Exposition, American Institute of Aeronautics and Astronautics, sep 1996. 
${ }^{12}$ Dworkin, S., Schaffer, A., Connelly, B., Long, M., Smooke, M., Puccio, M., McAndrew, B., and Miller, J., "Measurements and calculations of formaldehyde concentrations in a methane/N2/air, non-premixed flame: Implications for heat release rate," Proceedings of the Combustion Institute, Vol. 32, No. 1, 2009, pp. 1311-1318.

$\checkmark{ }^{13}$ Klein-Douwel, R. J. H., Jeffries, J. B., Luque, J., Smith, G. P., and Crosley, D. R., "CH and Formaldehyde Structures in Partially-Premixed Methane/Air Coflow Flames," Combustion Science and Technology, Vol. 167, No. 1, jun 2001, pp. 291-310.

-14 Brackmann, C., Nygren, J., Bai, X., Li, Z., Bladh, H., Axelsson, B., Denbratt, I., Koopmans, L., Bengtsson, P.-E., and Aldén, M., "Laser-induced fluorescence of formaldehyde in combustion using third harmonic Nd:YAG laser excitation," Spectrochimica Acta Part A: Molecular and Biomolecular Spectroscopy, Vol. 59, No. 14, dec 2003, pp. 3347-3356.

$\checkmark{ }^{15}$ Harrington, J. E. and Smyth, K. C., "Laser-induced fluorescence measurements of formaldehyde in a methane/air diffusion flame," Chemical Physics Letters, Vol. 202, No. 3-4, jan 1993, pp. 196-202.

${ }^{16}$ Dasari, A. and Gamba, M., "Characterization of Unsteady Combustion Phenomena in a University Scale Rocket Combustor," 53rd AIAA Aerospace Sciences Meeting, American Institute of Aeronautics and Astronautics, Kissimmee, FL, 2015, p. 15 . 